\title{
Early Childhood Curriculum Reform in Saudi Arabia Conceptualization of Theories in Early Childhood Curricula: Three Models
}

\author{
Sama Khomais ${ }^{1} \&$ Nahla Gahwaji ${ }^{1, *}$ \\ ${ }^{1}$ Childhood Studies Department, King Abdulaziz University, Jeddah, Saudi Arabia \\ *Correspondence: Childhood Studies Department, King Abdulaziz University, 4719, Jeddah 23617, Saudi Arabia. Tel: \\ 966-555-681-783. E-mail: ngahwaji@kau.edu.sa
}

Received: June 27, 2019

Accepted: July 23, 2019 Online Published: August 1, 2019

doi:10.5430/jct.v8n3p24

URL: https://doi.org/10.5430/jct.v8n3p24

\begin{abstract}
In recent developments, early childhood education in Saudi Arabia have captured political and governmental interests, conceiving the promising returns of investing in early years. This research has adopted an analytical descriptive approach through content analysis of curriculum philosophy (theories and principles) of three models of early childhood curricula. They were chosen deliberately, considering the elements of the curriculum, effectiveness in implementation and or achieving the desired learning outcomes. The selected curricula include, HighScope, Foundation Stage, and Te Whăriki. The analysis concludes that there is a general agreement about the structure and elements of EC curriculum. Perspective of children as learners, teachers' roles, learning environment are well profound in the three curricula supported by theoretical and empirical evidence. Nevertheless, challenges are still considered as opportunities for revising and evaluating our beliefs and understandings in order to maintain the improvements in ECE profession and to cope with the education reform in Saudi Arabia.
\end{abstract}

Keywords: early childhood, education reform, HighScope, foundation stage, Te Whāriki

\section{Introduction}

Complying with national and international trends, Saudi government has strong intentions to expand investment in early childhood education (ECE), which include education and care services for children from birth to eight. Young learners have been part of Saudi governmental development plans, when the first public nursery was launched in Riyadh in 1966, consequently followed by others in different areas of the country (Al-Hamed et al., 2007; Al-Sunbal et al., 2008). However, that was not the beginning of early year's education, since there were several earlier positive endeavors for establishing nurseries and preschools by the private sector. The first "Preschool Teacher Guide" was published in 1984, presenting the principles of working with preschool children (GPGE, 1984). In 1991, the widely known and implemented, The Developed Kindergarten Curriculum: Self-learning (DKC) was published as the official curriculum for both public and private preschools (GPGE, 1991). The DKC was up-to-date in its time, building on Piagetian views that emphasize providing rich learning environments that stimulate learning and development. Confronting practices that concentrate on rigorous subjects teaching, drawn down from elementary school, the holistic perspective considering all aspects of children's development was emphasized in the newly implemented curriculum (Khomais, 2007).

These innovative developments had accompanied the continuing social changes, where women had become active part of economic and workforce expansion (Gahwaji, 2006). These progressive standpoints towards women's roles, and the enhanced understanding of holistic human development had raised the need for developing professional practice in ECE. Accordingly, wide range professional development programs had took part in collaboration with UNESCO, in order to equip female teachers in the field with good practices that conform the DKC views (GPGE, 1991; MOE, 2005). Additionally, early childhood (EC) departments had been established in several Saudi Universities to fulfill the market needs for knowledgeable and well-trained professionals in teaching and leadership to serve in the broadly expanded public and private kindergartens.

While gaining more experience in ECE sector, the filed had gone through various changes and improvements, through either individual efforts or official plans. Lately, during 2015, the Ministry of Education in Saudi Arabia (SA) 
has commenced a huge reform for the whole education system including ECE (Gahwaji, 2016). One of the reform projects considers developing EC curriculum for Saudi practice. In this paper, we explore three international well-known EC curricula for their distinctive repetition in structure, elements, and outcomes. The analysis of the curricula concentrates on the theoretical background, the standpoints about teachers' role, and the position of children as learners. Exploring international perspectives of these elements could reveal contemporary directions in ECE, which might provide some guidance for official plans to reform EC curriculum in SA.

\subsection{Contemporary Directions in Early Childhood Curricula Reform}

It has been widely accepted that the main aim of the preschool stage should concentrate on preparing children for later learning in primary grades. Therefore, it is expected that the curriculum includes developmental goals that guide providing experiences to support preparation. These experiences embrace socio-emotional and psychomotor development, as well as cognitive development including knowledge and thinking and learning skills, devoting same weight for all aspects of development. Such practices should be developmentally appropriate, and aligned with children's abilities, needs, and interests, building on direct and hands-on learning experiences. Children need meaningful activities that are derived from and reflected on their everyday life experiences. Evolving construction and reconstruction of knowledge based on authentic and hands-on events and actions are of the basics of development. In order to do so, children ought to have, think over, talk about and interpret their imaginations (Burke \& Burke, 2005; Mclachlan, Fleer, \& Edwards, 2010; NAEYC, 2015).

In recent developments, ECE have captured political and governmental interests, conceiving the promising returns of investing in early years. It has been argued that when children have a good beginning of life, they become capable of creating brighter future for themselves and their communities. Much light is shed on terminology such as 'lifelong learning', 'early learning skills', 'good beginning', 'best start in life', 'learning from birth', and 'early learning framework' in EC, emphasizing the importance of considering the very early beginnings of learning. This vision has put more account on individuals to take the lead of themselves as learners, which entails innovative education systems that equip students with the knowledge, skills and dispositions needed for enduring success (Cheeseman, Sumsion, \& Press, 2014).

Such perspectives have put much pressure on the designers of EC curricula. Certainly, our understanding of learning depends on determining the noteworthy knowledge and skills for individual's achievements and productivity. This understanding spread over the way educators and practitioners interpret the goals in any curriculum. Taking into account that the majority of EC curricula adopt broad developmental goals, learning could be defined in different levels of breadth and depth, which span over a continuum starting from child-centered experiences to teacher-developed or even -directed practices. Nevertheless, the theoretical framework constitutes the backbone of any curriculum. It should provide profound understanding of the four elements of the curriculum, according to Schwab, which include the learner and the learning process, the teacher and the educational process, the content, and the learning environment (Posner, 2003).

Here comes the struggle between tending towards the views of developmental and educational psychology that support learning through exploration and play, against more emphasis on educational achievements in selected disciplines, to inform long-term economic and sociopolitical goals. This argument has taken place in various documents discussing whether or not ECE should be restructured to align with political demands, and providing evidence that raise caution of going towards this direction (Cheeseman, Sumsion, \& Press, 2014; Haslip \& Gullo, 2018; Moss et. al., 2016; Nitecki \& Wasmuth, 2017; Nyland \& Ng, 2016; Urban \& Swadener, 2016; Wood \& Hedges, 2016). The supporting views of political and economic demands have ignored the long lasting inheritance of EC philosophies and practices, which have a worldwide impact on curriculum frameworks, explaining how children think and learn. They explain most aspects of learning and development, and continue to upraise strategies complying with constructivist views, which mainly include free choice activities, interactions, shared thinking and learning, exploration and play (Edwards, 2005; Kostelnik, Soderman, \& Whiren, 2010; Mclachlan, Fleer, \& Edwards, 2010; NAEYC, 2015).

There are considerable evidences that play have a great influence on learning and development, where children learn, think and create while moving, using senses, and interacting with materials, peers and adults (Katz, 2015; NAEYC, 2015; Roopnarine \& Johnson, 2013; Whitebread, Basilio, Kuvalja \& Verma, 2012; Wood, 2013). Nevertheless, this does not clearly explain how academic content is acquired during play, particularly 'free play', nor it does specify the teachers' roles in such complicated process. These concerns have pushed towards implying more systematic teaching and learning frameworks in EC. That came along with economic and political demands that emphasize defined early educational outcomes in math and literacy, ignoring aspect such as social and emotional skills, arts and 
psychomotor skills as part of the child holistic development. From this point of view, teachers' roles can become specifiable and accountable within 'tight' education system and prescribed curriculum. Yet, these views do not provide sufficient justification for eliminating children's right of play, nor to explain why we have to defend such a profound right (Haslip \& Gullo, 2018; Nitecki \& Wasmuth, 2017; Wood \& Hedges, 2016).

In order to overcome such challenge, ECE field is in need for research-based evidence and professional dialogue that aims at finding new alternatives for compromising these two seemingly confronted perspectives. Goldstein (2007) argued that we must perceive our challenges in the field as encouraging opportunities for intellectual development that support the growth of profession. The image of the child, the purpose and function of working with children, the ways they learn and the best practices to support their learning and creativity without losing enjoyment and interests, should all be reconsidered. However, it is necessary to call attention that it is not about 'either/or' situation, as long as we believe that there is no dichotomy between play and learning (Moss et al., 2016; Nitecki \& Wasmuth, 2017; Urban \& Swadener, 2016; Wood \& Hedges, 2016). In OECD (2018) report about quality EC education and care, meta-analysis outcomes showed that it is not teachers' higher qualification, but teacher-child interactions that were associated and predictive of children emerging academic learning in literacy and numeracy, as well as behavioral and social development. Therefore, alternative understandings should not ignore children's right of play or confine the inclinations of their age, nor to force teachers to do what opposes their beliefs and knowledge or demolish their creativity. Detailed curriculum and control over teachers' everyday practices would put them under pressure and restrain their independence, motivation and inspiration. To the contrary, teachers should be considered as change agents in field reform projects, since they are the ones who transform theoretical perspectives into practice, and work as mediators of change for all parties in the field including parents (Nyland \& Ng, 2016; Choppin, McDuffie, Drake, \& Davis, In press).

However, lack of clarity causes a source of struggle when new directions are presented. The designers of the curriculum might not share the same point of view with practitioners, which affect implementation process and takes it to different intention other than the designers' (Choppin, McDuffie, Drake, \& Davis, In press; Nyland \& Ng, 2016; Oats, 2010). Choppin et al. (In press) describe the complexity faced in new conditions during practice. They highlight the difficulties a practitioner faces in decision making in complex environments, including controlling, perceiving, understanding and responding in changing situations. Such complexity is explained by the "the effect of cognitive load on decision making', which describes the difference between automatic spontaneous performance and controlled performance that require the use of working memory through attention; recall of knowledge and manipulation of experiences. Definitely, the complexity is increased if the environments encompass use of tools or machines. When a curriculum is newly presented, teachers use their previous knowledge, experience and beliefs to interpret and mediate theories and accompanying resources to put them into action. In this situation, different scenarios could occur. If the designers of the curriculum did not present their intentions clearly, teachers predominantly rely on their previous experience, or try to interpret it in ways that may or may not match the original meanings. Through repeated experience with the curriculum in real situations, familiarity and understandings gradually develop.

Taylor, Rhys and Waldron (2016) argue that teachers must consider the challenges in the field as part of their ongoing professional development. Therefore, dialogue and inspiring professional learning that motivate and empower teachers to become change agents comprises an essential part of reform plans, especially when it takes significant new direction. No doubt, this should be accompanied with whole education reform that includes dynamic developments in systems and environments. In addition, developed teacher preparation programs should be a part of the change, since they constitute the source for new workforce serving in a range of diverse settings (Crossley, 2015; Haslip \& Gullo, 2018; Nores, Figueras-Daniel, Lopez, \& Bernal, 2018).

After all, research should be the backbone for any new direction. No changes except evidence-based developments may take place in the field. Oates (2010) warns of borrowing policies from other nations or contexts, without adopting them to historical, theoretical, cultural and practical realities. Nothing should be taken for granted. Yet, curriculum reform can be informed by reviewing and comparing quality systems. On the other hand, there is a caution that the original meanings of theoretical perspectives and practices could be changed or interpreted differently over place and time (Nyland \& Ng, 2016). Therefore, authentic reform does not apply by just putting the meant polices into practice. Since beliefs lead actions, research-based revolution requires changing the culture and the educational environment. That cannot take place without collaboration with all stakeholders, including scholars and researchers, practitioners in the field as supervisors, school leaders and teachers, as well as parents (Haslip \& Gullo, 2018; Nyland \& Ng, 2016; Wiles \& Bondi, 2015). 


\section{Method}

The research adopted an analytical descriptive approach through content analysis of EC curricula. Content analysis is an organized and quantitative description of the apparent content of data. It is used to identify the extent to which curricula content includes main aspects of learning. It also relies on identifying regular recurrence of the analyzed points whether they are a paragraph or a lexical item. The analysis of curriculum content in this study consisted of philosophy (theories and principles) of the three models of EC curricula.

\subsection{Sample and Analyses of Curricula}

Despite the variety of the curricula presented to EC stage all over the world in terms of their details and aspects, some of them are distinctive and successful; their success differ from one place to another is due to several reasons. There are some obvious indicators of effective curricula, which include the following:

1. Theoretical frameworks that control curriculum goals are a leading guide to all curriculum components. The framework includes a view of child's learning, which affects the expected objectives, teaching strategies, methods of interaction with children, methods of organizing the environment as well as assessment tools.

2. The role of the teacher is regarded as the most important component of curriculum effectiveness. This is due to fact that the teachers' lack of knowledge or experience makes them unable to grasp learning philosophies and methods of interaction or teaching and assessment. This in turn badly affects the implementation of curriculum no matter if it includes a description of detailed professional practices or not.

3. Learning objectives and the expected outcomes to be achieved as a result of implementing the program.

\subsection{Sampling Procedures}

The sample of the study has been intentionally selected for availability of the above-mentioned components of curriculum and for its reputation of efficiency in application and outcomes. In addition, the selected curricula were lately revised, presenting new editions for practice. The researchers also were keen to have different perspectives from different parts of the world. The sample consisted of three curricula, which are HighScope Curriculum from USA, Early Years Foundation Stage from UK, and Te Whariki Curriculum from New Zealand.

The HighScope was built on research and longitudinal studies that began in 1962 to study the impact of EC programs on the performance of environmentally disadvantaged children in USA led by David Weikart. The HighScope Foundation for Educational Research was founded in 1970 and the first version of the curriculum was published in 1971. Since then, the Foundation has carried out numerous studies to verify the long-term positive effects of the program and to develop the curriculum (HighScope, n.d.). The latest research reported in the curriculum is the confirmation of new brain research scientists by world leaders Shore and others on the positive effects of positive child interaction through active learning on brain development (Epstein \& Hohmann, 2012).

The first phase of the Foundation Stage in UK, which was issued in 2003, took over five years, during which it was prepared and applied experimentally and continued to be followed up and developed for many years. Large number of academics, specialists and experts from various British universities and the National Foundation for Educational Research prepared it. Early Years Curriculum Group committee was formed to develop this curriculum, which included academics and educators from various British universities. The latest edition of it was updated in 2017 and is available on the Unit of Education (Department of Education-UK, 2017).

The first version of the official New Zealand curriculum; Te Whariki was published in 1996, followed by a number of studies. A report published in 2013 recommended a review of the curriculum and an opportunity for discussion by practitioners in order to develop a deeper understanding of its components and methods of implementation and guidance. The curriculum was developed by the Ministry of Education, by the Advisory Group on Early Learning (AGEL), with the participation of various groups of academics and practitioners in EC to develop the draft curriculum. The referendum results were submitted to final publication in 2017 (Education Evaluation Reports, 2013; Ministry of Education-NZ, 2017).

\subsection{Study Tool}

The content analysis form of curricula has been designed following these steps:

- Determining the main categories and components intended for analyses.

- Reviewing each curriculum theoretical background and principles components separately and identifying all their incorporated aspects. 
- In the initial content analysis form, components were organized in tables that show their vertical and horizontal sequence, to show their coherence and connection

- Identifying the components presented well in the form and those that are lacking organization or depth, and consequently determining the main weaknesses.

- Refining the form and overcoming weaknesses by making amendments and rearrangements of items presenting components.

\subsection{Study Procedures}

To achieve the study objectives, the study was conducted according to the following procedures:

1. Reviewing previous studies in EC and writing the study theoretical background.

2. Building the tool of the study (Content analysis form), presenting it to expert arbitrators for face validity and piloting it to a comparable sample to assess reliability and content validity.

3. Putting the final Content Analysis Form.

4. Analyzing and interpreting the findings of the content analysis form.

\section{Results \& Analysis}

The study has concentrated on two main components that determine the curricula philosophical perspectives, which include the theoretical background and the principles of the curricula. The analysis outcomes are presented in the following:

\subsection{Theoretical Background}

Early childhood education curricula are typically based on learning and developmental theories, which primarily consider learners' and teacher' roles, learning environment, and diverse teaching and learning strategies. Curricula differ in their approach of specifying the theoretical background, either by presenting it explicitly or by allowing readers to infer it from the educational content and strategies embraced (Wiles \& Bondi, 2015). The three curricula analyzed in this study varied between these two approaches, but most of them tended to review theories explicitly, some have even defined the relationship of exact parts to specific theories.

The childhood theories appeared clearly in both HighScope and Te Whariki, conversely to the Foundation Stage, where theories are highlighted indirectly in the principles, the role of play, and the emphasis on social interaction in learning through the document. All the curricula were built on the theories that form the basis of EC education. For instance, Piaget's cognitive theory and its role in the development of logical thinking through the child's exposure to many experiences and rich stimulating environment is one of these theories. In addition, the socio-cultural theory by Vygotsky, which focuses on the importance of social interaction in learning, and children's need for understanding and applying concepts, reflects the importance of language in the development of thinking and acquiring concepts. Vygotsky's theory is unique by the Zone of Proximal Development (ZPD) term, which describes what the child can do alone and can do with the help of others, including adults and peers. From his point of view, the social interaction is a fundamental factor for learning (Bodrova \& Leong, 2007; Edwards, 2005). Similarly, the play approach appeared strongly in all curricula as a central means for learning and a crucial need and right for children.

The environment plays a significant role in children's development and learning, as shown in the analyzed curricula frameworks. The three curricula have embraced the environmental theories of learning, which represent the bioecological model emphasizing the child's exposure to the surrounding environment and the exchange between the individual and the environment (Rimm-Kaufman \& Pianta, 2000). Te Whariki have underlined modern research and theories on brain development, which show that children are vulnerable to their surroundings making them quick learners, but are also vulnerable to negative factors, confirming that the biological basis is influenced by environmental factors. The HighScope cited the John Dewey's educational philosophy, which describes education as a social process, where interacting with others in rich environments is essential for better learning. In addition, it emphasizes the interactions between families' backgrounds, communities, and values, and school life (Epstein \& Hohmann, 2012; Siegler, \& Wanger, 2005).

Te Whariki is exceptional in adding some local theories that emphasizes culture and reciprocity such as Kaupapa Morori Theory, which is concerned with preserving the language, culture and history to form the basis for growth, development, learning, success and achievement in social, educational and economic aspects. Another approach is the The Pasifika, which deals with the interchangeability of people, places and cultures, enabling them to deal with 
familiar and unfamiliar worlds, and views children as treasures and future hopes that must be cared for by all members of the extended family (Smith, 2003). In addition, Te Whariki has called for the development of $21^{\text {st }}$ citizens, who are capable of responding to the changing demands of the interconnected worlds. In these new worlds, knowledge and learning are accelerated, which requires focusing on communication and collaboration skills to enable learners to succeed in their lifelong learning (Soffel, 2016). Table (1) shows the trends of the different theories and approaches that underline the basis of the curricula.

Table 1. Theoretical Background of the Analyzed Curricula

\begin{tabular}{lccc}
\hline \multicolumn{1}{c}{ Theoretical Backgrounds } & HighScope & Foundation Stage & Te Whariki \\
\hline Piaget & $\checkmark$ & $\checkmark$ & \\
Vygotsky & $\checkmark$ & $\checkmark$ & $\checkmark$ \\
Environmental theories & $\checkmark$ & $\checkmark$ & $\checkmark$ \\
John Dewey & $\checkmark$ & & $\checkmark$ \\
Brain theories & & & $\checkmark$ \\
Local theories & & & \\
\hline
\end{tabular}

\subsection{Principles of the Curricula}

The three curricula have put down a number of principles on which they are based, as the foundation for curriculum decisions making and guidance for all aspects of pedagogical practices. Therefore, these principles constitute a basis for teachers and practitioners to determine choices and make decisions in relation to children, content, teaching methods and strategies, learning environment, and the relationship with adults including teachers, families, and community. Table (2) illustrates the principles underlying each curriculum.

Table 2. The Principles of Curricula

\begin{tabular}{lll}
\hline \multicolumn{1}{c}{ HighScope } & \multicolumn{1}{c}{ Foundation Stage } & \multicolumn{1}{c}{ Te Whariki } \\
\hline - Active Learning & - Unique Child & • Empowerment \\
- Adult-Child Interaction & - Positive Relationships & • Holistic Development \\
- Learning Environment & - Enabling Environment & • Family and Community \\
- Daily Routine & - Children develop and learn in different ways & • Relationships \\
- Assessment & and at different rates & \\
\hline
\end{tabular}

By looking at the principles adopted by these curricula, we can see that they are mostly based on the elements of the curriculum identified by Schwab in: the learner and the learning process, the teacher and the educational process, the content, and the environment in which the learning process takes place (Posner, 2003).

The learner and the learning process: The learner in the principles of the curricula appeared in two complementary aspects, either by focusing on the nature of the learner and the characteristics of growth and needs, or by focusing on the learning process and its association with the nature of the learner. As for the nature of the learner, the Foundation Stage, for example, focused on the unique child as a basic principle, conceiving the child as an inherent learner from birth, capable of learning effectively, flexibly and confidently, meaning that each child has the capacity to learn as much as her/his potentials. Educational and positive relationships within these capabilities are suitable opportunities for learning. The Foundation Stage added the principle of growth and learning. According to this principle, children develop and learn in different ways and different paces reflecting the principle of exclusivity. Te Whariki has adopted the principle of comprehensive growth, which describes the child as an integrated holistic individual that needs to grow from all aspects in a balanced and interconnected manner, and that growth in one aspect affects the others. This requires focusing on the strengths of the child and considering them as a source and beginning of learning. Te Whariki has also focused on social and emotional development as a key factor for success in school and as an influential element in all other aspects of growth, including cognitive, sensory and motor, in addition to considering it as the basis for the child's integration and interaction in learning activities.

The HighScope has taken a different approach by focusing on the 'active' learning process, which involves the active participation of the learner in various interactions with tools, environment and people to achieve the learning objectives. Such an approach makes learners do most of the efforts, use their minds effectively, work to solve problems, and apply 
what they learn in different situations. By this way, the learner becomes responsible for the learning process, and this can only be done by dealing with the learner based on her/his developmental characteristics and needs at this stage (Mikser, Kärner \& Krull, 2016).

The teacher and the educational process: Similarly, this component of the curriculum appeared in two complementary aspects, either by focusing on the roles of the teacher, or on the process of education as one of these basic roles. The principle of interaction between teacher and children and the formation of positive relationships were clearly reflected by different names in the three analyzed curricula. All of them have reflected the role of teacher-learner relation in enriching the education process as a fundamental element in which education does not take its proper course without it. HighScope added evaluation as a principle, which is one of the basic components of the educational process that is interwoven within planning and implementation (Orlich et al., 2013). As it appears, the teacher's role in teaching is considered to be a vital aspect in curriculum execution (Gahwaji. 2013).

The content: Content is not an important component of ECE, since it is considered as a readiness for learning rather than a stage with specific educational content. The primary objective of this phase is to develop the learning skills needed for the subsequent learning in primary grades (Mclachlan, Fleer, \& Edwards, 2010). Nevertheless, EC curricula emphasize that the educational content must be responsive to the needs and interests of children and their desire to learn. Therefore, the content did not appear clearly in the principles of these curricula but was indirectly reflected in the principle of empowerment in Te Whariki. It emphasized that the content must be responsive to learners' needs, rich in experiences that enhance learning skills based on confidence in abilities and respect for equal opportunities (Soler \& Miller, 2003). The content also is indirectly demonstrated in all the analyzed curricula in the principle of the environment prepared for learning with rich and multiple experiences, being the medium in which children engage in learning activities.

The learning environment: All learning philosophies and theories have reinforced the role of the environment rich in experiences and stimuli in ECE, and which has been specified as an important component of the educational process. Rather, it has been defined as a third teacher in some philosophies (Beaty, 2014; Bullard, 2009). Therefore, the environment in the three curricula is an important aspect in the principles with different names, all of which reflect the importance of creating environments rich with stimulating experiences, exploration, sensory learning, and interaction, with emphasis on security and empowerment.

The principle of the relationship with family and community is an important component of the learning environment. That is based on the philosophies and approaches emphasizing that learning is not limited to the experiences of the child in the classroom or school, but occurs everywhere in school and outside, such as Vygotsky, Reggio Emilia, John Dewey, environmental theories, and modern research on the brain. Therefore, this principle has emerged prominently in all the analyzed curricula. Table (3) shows the connection between the principles underlying the three curricula and the elements identified by Schwab. The principles of these curricula show the representation of these elements in varying degrees according to the nature of ECE.

Table 3. The Connection between the Curricula Principles and the Curriculum Elements Identified by Schwab

\begin{tabular}{|c|c|c|c|c|}
\hline \multirow[b]{2}{*}{ Curriculum } & \multicolumn{4}{|c|}{ Elements of curriculum } \\
\hline & $\begin{array}{l}\text { The learner and } \\
\text { learning process }\end{array}$ & $\begin{array}{l}\text { The teacher and } \\
\text { educational process }\end{array}$ & The content* & $\begin{array}{l}\text { The learning } \\
\text { environment }\end{array}$ \\
\hline HighScope & - Active learning & $\begin{array}{l}\text { - Adult-Child } \\
\text { Interaction } \\
\text { - Assessment }\end{array}$ & $\begin{array}{l}\text { - Learning } \\
\text { Environment }\end{array}$ & $\begin{array}{l}\text { - Learning Environment } \\
\text { - Daily routine }\end{array}$ \\
\hline $\begin{array}{l}\text { The } \\
\text { Foundation } \\
\text { Stage }\end{array}$ & $\begin{array}{l}\text { - Unique child } \\
\text { - Development and } \\
\text { learning }\end{array}$ & - Positive relationships & $\begin{array}{l}\text { - Enabling } \\
\text { environment }\end{array}$ & $\begin{array}{l}\text { - Enabling environment } \\
\text { - Positive Relationships }\end{array}$ \\
\hline Te Whariki & $\begin{array}{l}\text { - Holistic } \\
\text { development }\end{array}$ & - Relationships & - Empowerment & $\begin{array}{l}\text { - Empowerment } \\
\text { - Family and } \\
\text { Community } \\
\text { - Relationships }\end{array}$ \\
\hline *represented & & & & \\
\hline
\end{tabular}




\section{Discussion}

\subsection{A Perspective for Saudi Curriculum Reform}

Specifying the principles upon which curricula are based is shown to be typical in ECE. They form a basis that guides practitioners in the field in making choices and taking decisions in all educational matters. The National Curriculum framework can embrace the four curriculum components specified by Schwab for determining its principles, bearing in mind the importance of adopting them to historical, theoretical, cultural and practical realities (Oates, 2010). Therefore, it is worth mentioning that because of Saudi culture privacy and for coping with rapid changes in social and economic structures, the National Curriculum framework should be based on a principle of identity and culture.

The views of developmental and educational psychology that consider children as respected individuals are still the bases for ECE. Therefore, the Saudi National Curriculum should show respect and appreciation to children with all their potentialities and uniqueness and make them the core and the source of the educational processes. This can become true through giving children a vital role in selection, planning and implementation in a way that guarantees being responsive to their needs and interests. Such perspective emphasizes culturally and developmentally appropriate practices that are derived from meaningful authentic experiences, which support learning through exploration, imagination and play. The best models have reflected learning in the exposure to direct experiences; through stimulating senses in discovery, problem solving, shared thinking in knowledge construction during social interaction. This approach makes it easier to conceive the connection between play and learning as double faces for one practice.

In order to achieve this vision, teacher's role in ECE requires designing environment and learning tools, planning activities, behavior guidance, adjustment and modification, assessment and report writing, considering individual differences, needs and interests. In addition, teachers have a vital responsibility in communication with children's families to have an active role in their education from all aspects. Moreover, a child in this stage still needs care beside education, which includes psychological and emotional elements that involve secure warm relationships. Due to this EC teachers' multiple-faced role, the National Curriculum framework should show clear understanding of these responsibilities, which represent the role of a caregiver, an educator and learning facilitator at the same time. For experienced teachers, conceivably it is better to let them create and innovate through new trends in ECE, without being restricted with a content framework that limits their experience and excellence meant to be presented to children.

On the other hand, the theoretical framework in curricula can be presented explicitly or embedded implicitly. However, Choppin et al. (In press) have warned of lack of clarity, as it could be a source of blunder. Therefore, obvious theoretical perspectives seem to be more convenient for sharing same views, since this could guide decision-making and implementation without ambiguity. This in turn contribute to putting theory into practice, which is one of the most important intentions of curricula designers and educators, so that theories do not remain away from reality; which leads to lack of improvements in educational practices according to theories and research outcomes.

As for the background theories, the most prominent are Vygotsky's socio-cultural theory and Paige's cognitive theory. These two theories are prevalent in EC curricula; they complete each other since both reflect constructivism perspective. However, the socio-cultural theory has showed the importance of social interaction in learning. As a result, it has become more apparent in EC curricula. In addition, other philosophies and theories were adopted in the curricula, such as John Dewey, modern theories about brain development, environmental and local theories. Therefore, taking into account the approaches utilized in these curricula, the designers of the Saudi National Curriculum could adopt all what support educational processes. Yet, Saudi practice cannot overlook the Islamic perspective in education; it is a basis and a life style, which we lead and are keen to transfer to the following generations. Hence, it is vital to set it as a general framework for the National Curriculum framework.

Since school curricula are the common culture among all members of a society, the National Curriculum must include enough part of cognitive, social and emotional content that focuses on identity, in order to protect citizens, increase their awareness and pride of their uniqueness, and lead their sense of unity through knowledge, skills, values and attitudes. Nevertheless, it is necessary to emphasize educational experiences that upraise children's awareness with the variety and difference in their environment and society. It is necessary to establish the culture of accepting the other and participating with them despite being different. This should be reflected in the curriculum framework through the respect of families' backgrounds and cultures in the selection of activities and experiences. Flexibility and willingness to modify or cancel any educational component that contradicts with families' beliefs or backgrounds 
represent these attitudes as well. Moreover, mother tongue has a special effect in supporting children's learning and development in all domains, and in learning a second language as well, while Arabic language has a special influence on identity, belonging and religious aspect.

\subsection{Conclusion}

It seems obvious that there is a general agreement about the structure and elements of EC curriculum. Perspective of children as learners, teachers' roles, learning environment are well profound in the literature supported by theoretical and empirical evidence. ECE is also unique and independent in its philosophical background about learning and development, presenting special understanding that leads practice in different direction other than conventional instructional practices that aims towards knowledge transmission with typical means. It retains long heritage of strong evidence-based progressive views about the importance of play, exploration, and social interaction for shared thinking and learning. All of which are difficult to be penetrated or doubt of without quality research-based developments. Nevertheless, challenges are still considered as opportunities for revising and evaluating our beliefs and understandings in order to maintain the improvements in ECE profession.

\section{Acknowledgements}

The researchers would like to thank Dr Shahd Qutub, Miss Bayan Shami, Miss Nouf Aljeaid, Miss Iman Abdulrahman who provided help during the research (writing assistance and curriculum analysis). Also, special thanks to the Ministry of Education for funding the research.

\section{References}

Al-Hamed, M. M., Zeyadah, M. A., Al-Otaibi, B. J., \& Mutawali, N. A. (2007). Education in The Kingdom of Saudi Arabia (4th ed.). Riyadh: Al Roshd Library. (Document in Arabic language).

Al-Sunbal, A. A., Al-Khateeb, M. S., Mutwali, M. M., \& Abduljawad, N. M. (2008). The Education System in the Kingdom of Saudi Arabia (8th ed.). Riyadh: Dar Al-Khareji for Publishing and Distribution. (Document in Arabic language).

Beaty, J. (2014). Preschool appropriate practice: Environment, curriculum, and development (4th ed.). Belmont, CA: Wadsworth Cengage Learning.

Bodrova, E., \& Leong, D. (2007). Tools of the mind: The Vygotskian approach to early childhood education (2nd ed.). Upper Saddle River, NJ: Pearson, Merrill Prentice Hall.

Burke, C. J F., \& Burke, W. M. (2005). Student-ready schools. Childhood education, 81(5), 281-285. https://doi.org/10.1080/00094056.2005.10521307

Cheeseman, S., Sumsion, J., \& Press F. (2014). Infants of the knowledge economy: the ambition of the Australian Government's Early Years Learning Framework. Pedagogy, Culture \& Society, 22(3), 405-424. http://dx.doi.org/10.1080/14681366.2014.914967

Choppin, J., McDuffie, A. R., Drake, C., \& Davis J. (In press). Curriculum ergonomics: Conceptualizing the interactions between curriculum design and use. International Journal of Educational Research, 92, 75-85. https://doi.org/10.1016/j.ijer.2018.09.015

Crossley, D. (2015). An Education worth Having: The Aspirations and the Development of the Whole Education Network in England. European Journal of Education, 5(2), 184-195. https://doi.org/10.1111/ejed.12121

Department of Education-UK (2017). Statutory framework for the early years foundation stage: Setting the standards for learning, development and care for children from birth to five. United Kingdom Government.

Education Evaluation Reports (2013). Working with Te Whariki. New Zealand: Educational Review Office.

Edwards, S. (2005). Constructivism does not only happen in the individual: sociocultural theory and early childhood education. Early Child Development and Care, 175(1), 37-47. https://doi.org/10.1080/0300443042000230311

Epstein, A. S., \& Hohmann, M. (2012). The HighScope preschool curriculum. Michigan, USA: HighScope Press.

Gahwaji, N. (2006). Designing a Tool for Evaluating the Quality of Preschool Education in Saudi Arabia. Published $\mathrm{PhD}$ Thesis, University of Exeter, Exeter, UK.

Gahwaji, N. (2013). Controversial and Challenging Concerns Regarding Status of Saudi Preschool Teachers. 
Contemporary Issues in Education Research, 6(3), 333-343. https://doi.org/10.19030/cier.v6i3.7905

Gahwaji, N. (2016). The Effects of Two Different Instructional Programmes on Literacy Skills of Kindergarten Children, Journal of International Education Research, 12(1), 13-26. https://doi.org/10.19030/jier.v12i1.9563

General Presidency of Girls Education (GPGE) (1984). Preschool Teacher Guide. Riyadh, Saudi Arabia: GPGE. (Document in Arabic language).

General Presidency of Girls Education (GPGE) (1991). The Developed Kindergarten Curriculum (DKC): The Individual Learning (1volume). Riyadh, Saudi Arabia: GPGE \& AGFUND. (Document in Arabic language).

Goldstein, L. (2007). Beyond the DAP versus standards dilemma: Examining the unforgiving complexity of kindergarten teaching in the United States. Early Childhood Research Quarterly, 22, 39-54. https://doi.org/10.1016/j.ecresq.2006.08.001

Haslip, M. J., \& Gullo, D. F. (2018). The Changing Landscape of Early Childhood Education: Implications for Policy and Practice. Early Childhood Education Journal, 46, 249-264. http://10.1007/s10643-017-0865-7

HighScope. (n.d.). HighScope. Retrieved on 30/10/2017 from: https://highscope.org

Katz, L. (2015). Lively minds: Distinctions between academic versus intellectual goals for young children. Defending the Early Years. Retrieved Oct. 28, 2018, from https://www.deyproject.org/uploads/1/5/5/7/15571834/dey-lively-minds-4-8-15.pdf

Khomais, S. (2007). Children's Early Understanding of Number in Home and Preschool Contexts in Saudi Arabia. Published PhD Thesis, University of Exeter, Exeter, UK.

Kostelnik, M. J., Soderman, A. K., \& Whiren, A. P. (2010). Developmentally appropriate curriculum: Best practices in early childhood education (5th ed.). Upper Saddle River, NJ: Pearson Merrill/Prentice Hall. ISBN \# 9780131381445

Mclachlan, C., Fleer, M., \& Edwards, S. (2010). Early childhood curriculum: Planning, assessment, and implementation. London, UK: Cambridge University Press.

Mikser, R., Kärner, A., \& Krull, E. (2016). Enhancing teachers' curriculum ownership via teacher engagement in state-based curriculum-making: the Estonian case. Journal of Curriculum Studies, 48(6), 833-855. http://10.1080/00220272.2016.1186742

Ministry of Education-NZ (2017). Te Whariki: Early Childhood Curriculum. Wellington: New Zealand Government.

Ministry of Education - SA. (2005). The Developed Kindergarten Curriculum: Self-learning (DKC) (seven volumes). Riyadh, Saudi Arabia: MOE \& AGFUND. (Document in Arabic language).

Ministry of Education-SA (2015). Kindergartens Programs. Retrieved 6/1/2018 from https://www.moe.gov.sa/ar/news/Pages/ryadatfalfr.aspx

Moss, P., Dahlberg, G., Mantovani, S., May, H., Pence, A., Rayna, S., Swadener, B., \& Vandenbroeck, M. (2016). The Organisation for Economic Co-operation and Development's International Early Learning Study: Opening for debate and contestation. Contemporary Issues in Early Childhood, 17(3), 343-351. https://doi.org/10.1177/1463949116661126

National Association for the Education of Young Children (NAEYC). (2015). Developmentally appropriate practice in early childhood programs serving children from birth through age 8. Retrieved Oct. 31, 2018 from http://www.naeyc.org/DAP

Nitecki, E., \& Wasmuth, H. (2017). Global trends in early childhood practice: Working within the limitations of the global education reform movement. Global Education Review, 4(3), 1-13.

Nores, M., Figueras-Daniel, A., Lopez, M. A., \& Bernal R. (2018). Implementing aeioTU: quality improvement alongside an efficacy study-learning while growing. Annals of the New York Academy of Science, 1419, 201-217. https://doi.org/10.1111/nyas. 13662

Nyland, B., \& Ng J. (2016). International perspectives on early childhood curriculum changes in Singapore and Australia. European Early Childhood Education Research Journal, 24(3), 465-476. https://doi.org/10.1080/1350293X.2015.1102416

Oates, T. (2010). Could do better: Using international comparisons to refine the National Curriculum in England. Retrieved

from 
http://www.cambridgeassessment.org.uk/images/112281-could-do-better-using-international-comparisons-to-ref ine-the-national-curriculum-in-england.PDF

Organization for Economic Co-operation and Development (OECD) (2018). Starting Strong: Engaging Young Children: Lessons from Research about Quality in Early Childhood Education and Care. Paris: OECD Publishing. https://doi.org/10.1787/9789264085145-en

Orlich, D. C., Harder, R. J., Callahan, R. C., Trevisan, M. S., Brown, A. H., \& Miller, D. E. (2013). Teaching strategies: A guide to effective instruction (10th ed.). Belmont, CA: Wadsworth Cengage Learning.

Posner, G. (2003). Analyzing the Curriculum (3rd ed.). NY, USA: McGraw-Hill Higher Education.

Roopnarine, J., \& Johnson, J. (Eds.). (2013). Approaches to early childhood education. (6th ed.). New York, NY: Pearson.

Siegler, R. S., \& Wagner Alibali, M. (2005). Children's thinking (4th ed.). Upper Saddle River, NJ: Pearson Prentice Hall.

Smith, G. H. (2003). Kaupapa Maori Theory: Theorizing indigenous transformation of education \& schooling. Paper presented at AARE / NZARE Joint Conference, Auckland, N.Z, December 2003.

Soffel, J. (2016). What are the 21st century skills every student needs? World Economic Forum, weforum.org. $\begin{array}{llll}\text { Retrieved } \quad \text { October } 5 / 2018 & \text { from }\end{array}$ https://www.weforum.org/agenda/2016/03/21st-century-skills-future-jobs-students/

Soler, J., \& Miller L. (2003). The struggle for early childhood curricula: A comparison of the English Foundation Stage Curriculum, Te Wha"riki and Reggio Emilia. International Journal of Early Years Education, 11(1), 57-68. https://doi.org/10.1080/0966976032000066091

Taylor C., Rhys M., \& Waldron S. (2016). Implementing curriculum reform in Wales: the case of the Foundation Phase. Oxford Review of Education, 42(3), 299-315. https://doi.org/10.1080/03054985.2016.1184872

Urban, M., \& Swadener, B. B. on behalf of Reconceptualising Early Childhood Education (2016). Democratic accountability and contextualized systemic evaluation. A comment on the OECD initiative to launch an International Early Learning Study (IELS). Retrieved Oct. 31, 2018, from http://receinternational.org/RECE-comment-on-OECD-ICCPS.html\#sthash.Hu4zXt27.CibLb4ph.dpbs

Whitebread, D., Basilio, M., Kuvalja, M., \& Verma, M. (2012). The importance of play: A report on the value of children's play with a series of policy recommendations. Brussels, Belgium: Toys Industries for Europe. $\begin{array}{lllll}\text { Retrieved } & \text { Oct. } & 28, & \text { 2018, }\end{array}$ http://www.importanceofplay.eu/IMG/pdf/dr_david_whitebread_-_the_importance_of_play.pdf

Wiles. J.W., \& Bondi, J. C. (2015). Curriculum development: A guide to practice (9th ed.). Upper Saddle River, NJ: Pearson Education.

Wood, E., \& Hedges H. (2016). Curriculum in early childhood education: critical questions about content, coherence, and control. The Curriculum Journal, 27(3), 387-405. http://dx.doi.org/10.1080/09585176.2015.1129981

Wood, E. (2013). Play, learning and the early childhood curriculum (3rd ed.). London: Sage. 